$\begin{array}{cc}\text { ACADEMIA ROMÂNĂ } & \text { Rev. Roum. Chim., } \\ \text { 2020, 65(4), 395-401 }\end{array}$

\title{
SYNTHESIS OF NOVEL SUGAR BASED XANTHATES FOR THE REMOVAL OF COPPER AND NICKEL HARMFUL HEAVY METALS FROM WATER
}

\author{
Amar NATH ${ }^{\mathrm{a}, *}$ and Poorn Prakash PANDE ${ }^{\mathrm{b}}$ \\ ${ }^{\mathrm{a}}$ Department of Chemistry B.R.D.P.G. College Deoria, Zip code 274001, India \\ ${ }^{b}$ Department of Chemistry and Environmental Science, M.M.M. University of Technology, 273010, India
}

Received March 20, 2020

Sugar based xanthates viz $\boldsymbol{D}$-sorbitol xanthate and $\boldsymbol{D}$-mannitol xanthate (DSX1, DSX2, DMX1 and DMX2) have been synthesized by the reaction of $\boldsymbol{D}$-sorbitol (DS)/ D-mannitol (DM) with carbon disulfide $\left(\mathrm{CS}_{2}\right)$ in basic medium at room temperature by varying carbon disulphide and base ratio with respect to sugars. The synthesized xanthates were extracted with ether, and dried in air. The xanthates were characterized by micro analytical data, Elemental analysis (C, H, O, S), Fourier transform infrared (FTIR) spectroscopy, and ${ }^{1} \mathrm{H}$ nuclear magnetic resonance (1HNMR) spectroscopy. The synthesized xanthates were used for the removal of $\mathrm{Cu}^{2+}$ and $\mathrm{Ni}^{2+}$ form aqueous solutions. The metal complexes formed during the process of removal of metal ions were confirmed with FTIR spectroscopy. The removal of copper and nickel metal from water was quantitatively determined by UV-visible absorption spectroscopy.

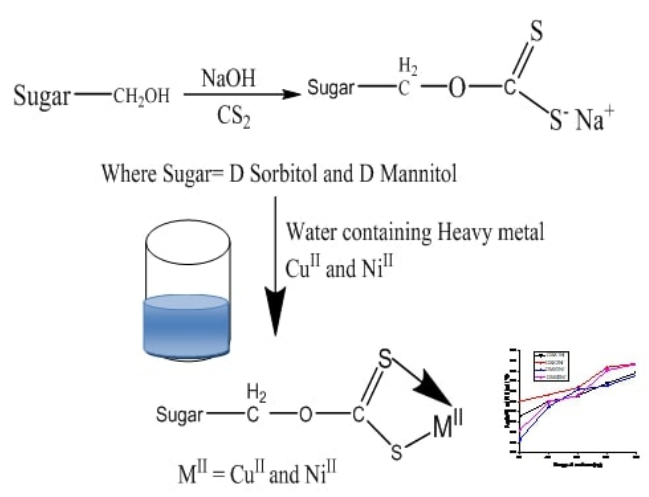

\section{INTRODUCTION}

Today humanity is facing the serious problem of water pollution caused by heavy metals like copper and nickel. ${ }^{1-3}$ Due to the rapid growth of industrial technology, a huge quantity of untreated wastewater is released into the environment which represents severe universal environmental problems. ${ }^{4-5}$ It is essential to remove the toxic heavy metals from wastewater before draining it into the environment. ${ }^{6-7}$ Although a number of heavy metals are essential for the human body in trace amount, after certain concentration level these metals cause adverse effect on human, plants and other living being. Nickel and Copper are essential elements in living beings which are involved in various metabolic processes, but these elements become hazardous above the maximum permissible limits. Ni is not a cumulative toxin, but exposure at higher concentration makes it toxic and even carcinogenic. ${ }^{8}$ Higher concentration of $\mathrm{Cu}^{2+}$ ion causes Alzheimer's disease. ${ }^{9}$ Several methods have been used for the removal of heavy metals from wastewater, like precipitation, complexation, flotation, solvent extraction, adsorption, membrane processing and electrolysis. ${ }^{10} \mathrm{~A}$ variety of chemicals have been utilized in the treatment of wastewater like activated carbon, ${ }^{11,12}$ polyacrylamide ${ }^{13}$ lignin and its derivatives ${ }^{14-16}$ branched polyethylenimine (PEI), sodium dodecyl sulfate (SDS) ${ }^{17-19}$ etc. Low-cost and environment friendly inorganic-organic composite membranes have been used for aquatic dyes removal $^{20} . \mathrm{CS}_{2}$-modified alkaline $\operatorname{lignin}^{21}$ carboxymethyl cellulose-immobilized $\mathrm{Fe}_{3} \mathrm{O}_{4}$ nanoparticles $^{22,23}$ poly(acrylic acid-co-acrylamide)-sawdust composite, ${ }^{24}$ Chitosan solution, ${ }^{25}$ polysaccharides and other coagulant/flocculants ${ }^{26,27}$ have also been used in

${ }^{*}$ Corresponding author: a.nath76.brdpg@gmail.com 
wastewater treatment, but these have some limitations. Generally, natural and synthetic flocculants are used alone in wastewater treatment which generates flocs and heavy metals are co-precipitated with flocculants, however this process has low capability towards removal of heavy metal ions. ${ }^{28}$ Therefore, other methods viz. chemical precipitation, electrolysis, ion exchange, reverse osmosis must be used for the removal of heavy metal ions from industrial effluents. These methods are not cost effective and may cause undesirable changes in the property of treated water.

The sulfides of heavy metals have very low solubility products, a fact which has attracted the attention of researchers towards the use of these compounds for the removal of heavy metals through the formation of metal sulfide complexes. ${ }^{29}$ Similarly, xanthates, which belong to the sulfur containing organic species, have also attracted the attention of researchers for the removal of heavy metals. Because of the ability of formation of coordination complex, xanthates have been used as a reagent in the analytical determination and separation of a number of metal ions. ${ }^{30,31} \mathrm{~A}$ number of polymeric xanthates have been synthesized and used for the wastewater treatment, however only a few monosaccharide based xanthates such as xanthates of the 2-deoxy $\boldsymbol{D}$-Ribose and $\boldsymbol{D}$-xylose have been synthesized. ${ }^{32}$ In this paper we report the synthesis and characterization of the xanthates of $\boldsymbol{D}$-sorbitol and $\boldsymbol{D}$-mannitol and also their use for the removal of copper and nickel ions from wastewater.

\section{EXPERIMENTAL}

\section{General}

D-Sorbitol, D-Mannitol, Carbondisulphide, Sodium hydroxide, Nickel Sulphate and copper sulphate (analytical grade 99.9\% pure) were obtained from S. D. Fine- Chem. Ltd, andused as received. The solvents used were of analytical grade. The synthesized compounds were identified by micro analytical data. Elemental analyses of $\mathrm{C}, \mathrm{H}, \mathrm{O}$ and $\mathrm{S}$ were performed using elemental analyzers Euro-E 3000 instruments. FTIR spectra ( $\mathrm{KBr}$ discs) were recorded on a Bruker FT-IR spectrophotometer within $400-4000 \mathrm{~cm}^{-1}$ range. 1HNMR spectra were recorded on Burker 400MHz NMR, Advanced III spectrometer. The products formed during the removal of metal ion from water were confirmed by the IR spectra $(\mathrm{KBr}$ discs) and amount of metal ion determined by the UV-visible absorption, Microprocessor UV-visible double beam spectrophotometer L1-2700 using wavelength range 200-800 nm.

\section{Synthesis of $D$ - sorbitol and $D$ - mannitol xanthates}

$\boldsymbol{D}$-Sorbitol and $\boldsymbol{D}$-Mannitol xanthates (DSX and DMX) (Scheme 2 and 3) were synthesized by mixing equvimolar amount of sugar $3.64 \mathrm{~g}(20 \mathrm{mmole})$ and Sodium hydroxide $0.8 \mathrm{~g}$ (20 mmole) dissolved in $25 \mathrm{~mL}$ distilled water and put into two neck $100 \mathrm{~mL}$ round flask with constant stirring for $1.5 \mathrm{~h}$ at $80^{\circ} \mathrm{C}$, after that reaction mixture cooled at room temperature, then $31.6 \mathrm{~g}$ ( $20 \mathrm{mmole})$ carbon disulphide was added into the reaction mixture with constant stirring at room temperature for about $12 \mathrm{~h}$, and an orange color turbid solution was obtained. The resulting product was extracted with ether and dried in air. The synthetic and elemental analysis detail of various grades of xanthates are given in Table 1 .

\section{Removal of $\mathrm{Cu}^{\mathrm{II}}$ and $\mathrm{Ni}^{\mathrm{II}}$ by DSX and DMX experiments}

The removal of metal ions by the complexation methods has been performed in $100 \mathrm{~mL}$ glass beakers using $100 \mathrm{mg}$. $80 \mathrm{mg}, 60 \mathrm{mg}, 40 \mathrm{mg}$ and $20 \mathrm{mg}$ quantity of the xanthates DSX1, DSX2, DMX1 and DMX2 as complexing agents and $50 \mathrm{~mL}(1 \mathrm{mg} / \mathrm{mL})$ stock solutions of metal ion. The stock solution of $\mathrm{Cu}^{\mathrm{II}}$ and $\mathrm{Ni}^{\mathrm{II}}$ were prepared by dissolving appropriate amount $0.329 \mathrm{mg}(1000 \mathrm{mg} / \mathrm{L})$ of $\mathrm{CuSO}_{4} \cdot 5 \mathrm{H}_{2} \mathrm{O}$ and $0.5125 \mathrm{mg}(1000 \mathrm{mg} / \mathrm{L})$ of $\mathrm{NiSO}_{4}$ in $100 \mathrm{~mL}$ distilled water. The solution with xanthates of each beaker was stirred for about $8 \mathrm{~h}$ at room temperature. After 2 hours the precipitates of metal xanthates settle down at the bottom of the beaker and are separated easily by filtration. The blackish and greenish precipitate of copper xanthate, and nickel xanthate were obtained respectively. The concentration of the metal ion present in the solution after complexation reaction was determined by UV-visible spectroscopy. The wavelength used for the determination of $\mathrm{Cu}^{2+}$ was $380 \mathrm{~nm}$ and for $\mathrm{Ni}^{2+}$ was $590 \mathrm{~nm}$. The total percentage removal of metal ion was calculated by the equation 1 .

$$
Q=\frac{C_{o}-C_{e}}{C_{o}} \times 100
$$

where $\mathrm{Q}=$ Percentage removal of metal ion after $8 \mathrm{~h}$.

$\mathrm{Co}=$ Initial concentration of metal ion

$\mathrm{Ce}=$ Concentration of metal ion after $8 \mathrm{~h}$.

\section{RESULTS AND DISCUSSION}

\section{Preface}

The two new sugar xanthates DSX and DMX were were synthesized by the reaction of carbon disulphide with $\mathrm{D}$ sorbitol and D mannitol respectively in basic medium. The formation of the xanthates was confirmed by their elemental analysis, ${ }^{1}$ HNMR and FTIR spectra. The preparation of sugar based xanthates by changing the ratio of sugar, sodium hydroxide and carbon disulphide (1:1:1 and 1:2:2) areshown in Scheme 1 and 2. 
Table 1

Synthetic ratio, molecular weight, $\mathrm{C}, \mathrm{H}, \mathrm{N}, \mathrm{O}, \mathrm{S}$ percentage

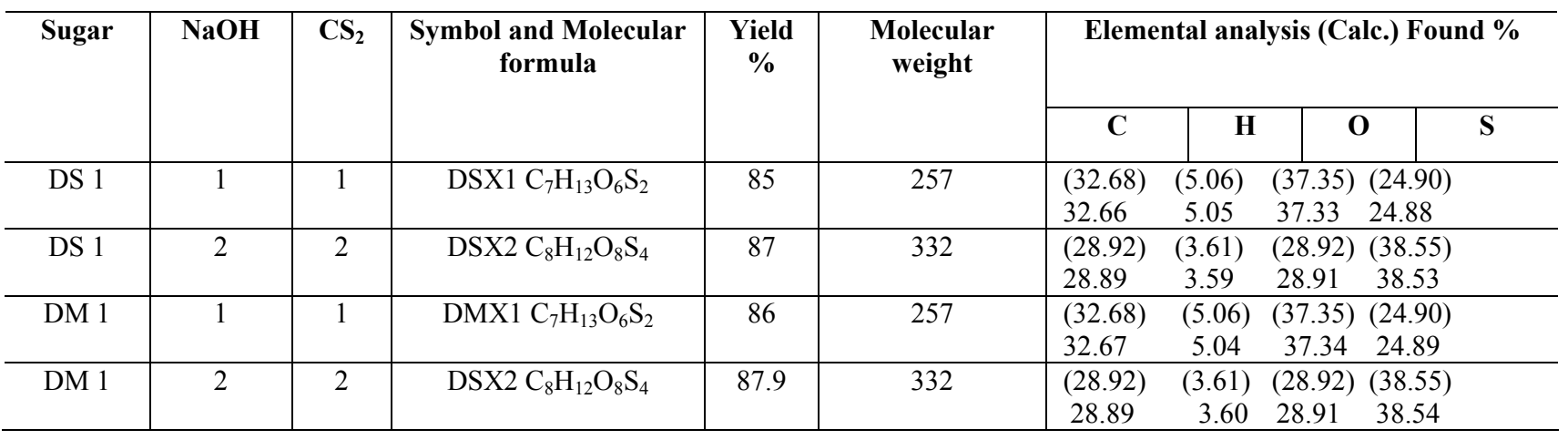

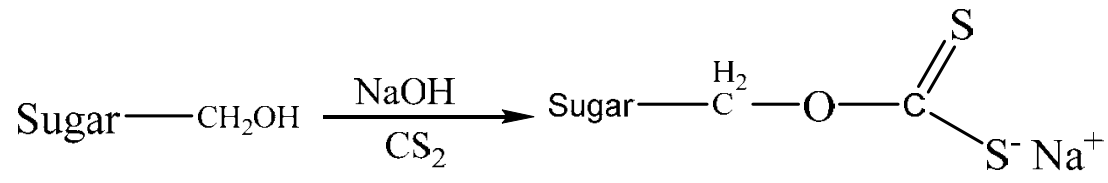

Where Sugar $=\boldsymbol{D}$-Sorbitol or $\boldsymbol{D}$ - Mannitol

Scheme 1 - Synthetic route for sugar based xanthates of sugar, $\mathrm{NaOH}$ and $\mathrm{CS}_{2}$ ratio $(1: 1: 1)$.<smiles>[14CH3][14C](O)([Ge])OC[Se]CO</smiles>

Sugar $=\boldsymbol{D}$-Sorbitol or $\boldsymbol{D}$-Mannitol<smiles>S=C(S)OC[Se]COC(=S)S</smiles>

Scheme 2 - Synthetic route for sugar based xanthates of sugar, $\mathrm{NaOH}$ and $\mathrm{CS}_{2}$ ratio $(1: 2: 2)$.

\section{FTIR study}

In the Table 1 FT-IR spectra of xanthates, (DSX1, DSX2, DMX1 and DMX2) have been recorded before and after $\mathrm{M}^{\mathrm{II}}$ ion $\left(\mathrm{M}^{\mathrm{II}}=\mathrm{Cu}^{\mathrm{II}}\right.$ and $\left.\mathrm{Ni}^{\mathrm{II}}\right)$ complexation. There are a series of characteristic bands for xanthates. A broad absorption peak in between $3368-3393 \mathrm{~cm}^{-1}$ that indicates $-\mathrm{OH}$ group stretching, $1632-1639 \mathrm{~cm}^{-1}-\mathrm{OH}$ bending, presence of absorption peaks in between $1206-1230 \mathrm{~cm}^{-1}$ characteristics peaks of $-\mathrm{O}-\mathrm{C}(=\mathrm{S})-\mathrm{S}^{33}$ which indicates that $\mathrm{CS}_{2}$ molecule attached with the sugar compounds and $1015-1018 \mathrm{~cm}^{-1}$ peaks illustrate the -C-O-C- group present in xanthates compounds. FT-IR spectra analyzed after xanthates metal ion
$\left(\mathrm{Cu}^{\mathrm{II}}\right.$ and $\left.\mathrm{Ni}^{\mathrm{II}}\right)$ complexation the observed peaks of DSX1M ${ }^{\mathrm{II}}, \mathrm{DSX} 2 \mathrm{M}^{\mathrm{II}}, \mathrm{DMX}^{\mathrm{II}}$ and DMX2M ${ }^{\mathrm{II}}\left(\mathrm{Cu}^{\mathrm{II}}\right.$ and $\left.\mathrm{Ni}^{\mathrm{II}}\right)$ are $3350-3354 \mathrm{~cm}^{-1}, 3365-3367 \mathrm{~cm}^{-1}$, $3344-3348 \mathrm{~cm}^{-1}$ and $3352-3355 \mathrm{~cm}^{-1}$ clearly indicate that $-\mathrm{OH}$ group is present in all metal xanthates. The shifting of absorption peaks of 1296-1230 $\mathrm{cm}^{-1}$ into $1142-1189 \mathrm{~cm}^{-1}$ and $1142-1189 \mathrm{~cm}^{-1}$ to 1027 $1045 \mathrm{~cm}^{-1}$ point toward the involvement of $-\mathrm{C}(=\mathrm{S})$ $\mathrm{S}$ group into complex formation with metal ion. But the presence of weak absorption peaks 1224$1226 \mathrm{~cm}^{-1}$ and $1072-1085 \mathrm{~cm}^{-1}$ in $\mathrm{DSX} 2 \mathrm{Cu}^{\mathrm{II}}$, DSX2Ni ${ }^{\text {II }}, D M X 2 \mathrm{Cu}^{\mathrm{II}}$ and DMX2NiI ${ }^{\mathrm{II}}$ complexes obviously explained that only one $-\mathrm{C}(=\mathrm{S})-\mathrm{S}$ group participate in complex formation shown in Figure 1.

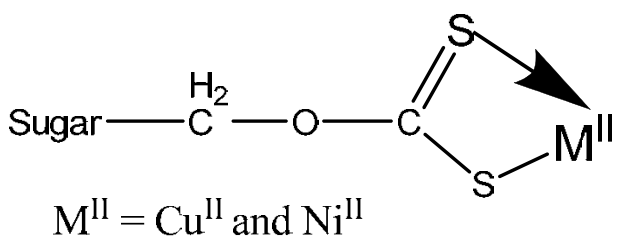

Fig. 1 - Xanthates metal complexes. 


\section{3. ${ }^{1}$ HNMR study}

${ }^{1} \mathrm{HNMR}$ data $\delta 3.58(4 \mathrm{H}$ of secondary $-\mathrm{OH}), \delta$ $3.65(1 \mathrm{H}$ of primary $-\mathrm{OH}), \delta 3.37$ and $3.38 \mathrm{~m}(4 \mathrm{H}$ of $-\mathrm{CH}-), \delta 3.81$ and $\delta 3.356 \mathrm{~m}$ (4H of $2-\mathrm{CH}_{2}$ group) of the DSX1, $\delta 3.56(4 \mathrm{H}$ of secondary $-\mathrm{OH}), \delta 3.35$ and $3.37 \mathrm{~m}(4 \mathrm{H}$ of $-\mathrm{CH}-), \delta 3.79$ and $\delta 3.354 \mathrm{~m}(4 \mathrm{H}$ of 2- $\mathrm{CH}_{2}$ groups) of xanthates DSX2, and nearly same spectral data were obtained xanthates DMX1 and DMX2 respectively which confirmed that only one CS2 molecule attached with primary $-\mathrm{CH} 2 \mathrm{OH}$ group of sugar in sugar, base and carbon disulphide ratio 1:1:1 and formed DSX1 and DMX1 compounds, while the above ratio changed as 1:2:2, DSX2 and DMX2 compounds were obtained in which two CS2 molecule attached with both $\mathrm{CH} 2 \mathrm{OH}$ groups of sugar.

\section{UV-visible absorption study}

The performance of xanthates in the removal of $\mathrm{CuII}$ and NiII ion from water was evaluated by complxation process are described above in experimental. The results of UV-visible absorption and percentage removal of metal ion are discussed as follows:

\subsection{The effect of xanthates dosage of $U V$-visible absorption of $\mathrm{Cu}^{I I}$ and $\mathrm{Ni}^{\text {II }}$ ion solution}

The xanthates dosages are of more significant to identify UV-visible absorption .The results are shown in Figure 2 and 3. It shows that the UVvisible absorption of metal ions is decreasing with increasing dosage of xanthates. It seems to be a stoichiometric relationship between metal ions and xanthates can be explained as: (Scheme 3).

\subsection{Effect of xanthates dosage on percentage removal of $\mathrm{Cu}^{I I}$ and $\mathrm{Ni}^{\text {II }}$ from water}

With the help of UV-visible absorption and equation 1 , percentage removals of $\mathrm{Cu}^{\mathrm{II}}$ and $\mathrm{Ni}^{\mathrm{II}}$ ions are calculated and results are illustrated in figure 4 and 5. The Results shows that $100 \mathrm{mg}$ of xanthates DSX1 and DMX1 have optimum removal metal ion removal capacity while at same experimental environment xanthates grades DSX2 and DMX2 required only $80 \mathrm{mg}$ for optimum removal capacity.

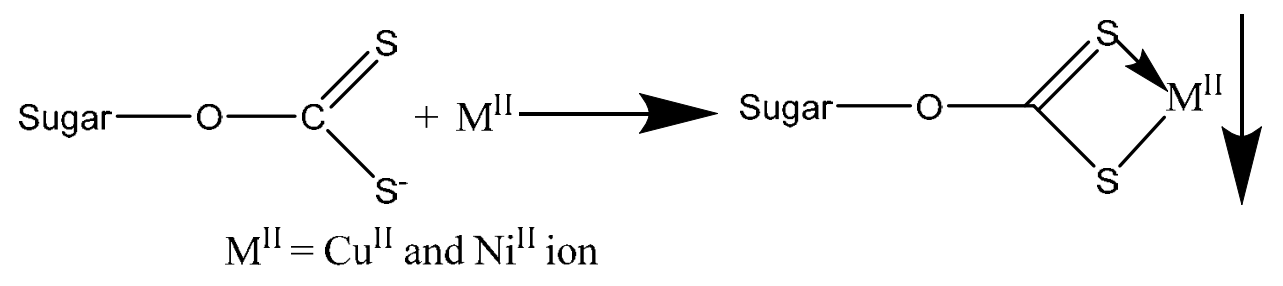

Scheme 3 - Formation of metal- xanthate complexes.

Table 2

Frequency ofIR spectra of sugar xanthates and its metal complexes

\begin{tabular}{|c|c|c|c|c|c|}
\hline Compound & $\begin{array}{c}\text { IR } \\
\text { frequency } \\
(\mathrm{cm}-1)\end{array}$ & Assignment & Compound & $\begin{array}{c}\text { IR frequency } \\
(\mathrm{cm}-1)\end{array}$ & Assignment \\
\hline DSX1 & $\begin{array}{l}3373 \\
1637 \\
1216 \\
1098 \\
1016\end{array}$ & $\begin{array}{l}\text { O-H Stretching } \\
\text { O-H Bending } \\
20 \\
-\mathrm{C}=\mathrm{S} \text { and C-S group } \\
\end{array}$ & DMX1 & $\begin{array}{l}3368 \\
1632 \\
1206 \\
1078 \\
1015\end{array}$ & $\begin{array}{l}\text { O-H Stretching } \\
\text { O-H Bending } \\
\text {-C }=\text { S and C-S group } \\
\text { " } \\
-\mathrm{C}-\mathrm{O}-\text { group }^{35}\end{array}$ \\
\hline DSX1 Cu & $\begin{array}{l}3354 \\
1633 \\
1149 \\
1038 \\
1014\end{array}$ & $\begin{array}{l}\text { O-H Stretching } \\
\text { O-H Bending } \\
20 \\
-\mathrm{C}=\mathrm{S} \text { and } \mathrm{C}-\mathrm{S} \text { group } \\
\text { "coordinate to } \mathrm{Cu}^{\text {II }} \\
-\mathrm{C}-\mathrm{O}-\text { group }\end{array}$ & $\mathrm{DMX} 1 \mathrm{Cu}$ & $\begin{array}{l}3350 \\
1630 \\
1143 \\
1027 \\
1013\end{array}$ & $\begin{array}{l}\text { O-H Stretching } \\
\text { O-H Bending } \\
\text {-C }=\mathrm{S} \text { and C-S group } \\
\text { 'coordinate to } \mathrm{Cu}^{\text {II }} \\
\text {-C-O- group }\end{array}$ \\
\hline
\end{tabular}


Table 2 (continued)

\begin{tabular}{|c|c|c|c|c|c|}
\hline DSX1 Ni & $\begin{array}{l}3348 \\
1636 \\
1145 \\
1038 \\
1013\end{array}$ & $\begin{array}{l}\text { O-H Stretching } \\
\text { O-H Bending } \\
\text { 20 } \\
-\mathrm{C}=\mathrm{S} \text { and } \mathrm{C}-\mathrm{S} \text { group } \\
\text { "coordinate to } \mathrm{Ni}^{\mathrm{II}} \\
-\mathrm{C}-\mathrm{O} \text { - groupp }\end{array}$ & DMX1 Ni & $\begin{array}{l}3344 \\
1634 \\
1142 \\
1028 \\
1012\end{array}$ & $\begin{array}{l}\text { O-H Stretching } \\
\text { O-H Bending } \\
\text { 34 } \\
-\mathrm{C}=\mathrm{S} \text { and C-Sgroup } \\
\text { "coordinate to Ni } \\
\text {-C-O- group }\end{array}$ \\
\hline DSX2 & $\begin{array}{l}3393 \\
1639 \\
1230 \\
1087 \\
1017\end{array}$ & $\begin{array}{l}\text { O-H Stretching } \\
\text { O-H Bending }{ }^{20} \\
-\mathrm{C}=\mathrm{S} \text { and C-S group } \\
{ }^{9} \\
-\mathrm{C}-\mathrm{O}-\text { group }^{9}\end{array}$ & DMX2 & $\begin{array}{l}3383 \\
1637 \\
1229 \\
1076 \\
1018\end{array}$ & $\begin{array}{l}\text { O-H Stretching } \\
\text { O-H Bending }{ }^{34} \\
-\mathrm{C}=\mathrm{S} \text { and C-Sgroup } \\
\\
\text { "C-O- } \text { group }^{35}\end{array}$ \\
\hline $\mathrm{DSX} 2 \mathrm{Cu}$ & $\begin{array}{l}3365 \\
1633 \\
1228 \\
1085 \\
1189 \\
1045 \\
1012\end{array}$ & $\begin{array}{l}\text { O-H Stretching }{ }^{20} \\
\text { O-H Bending }{ }^{20} \\
-\mathrm{C}=\mathrm{S} \text { and C-S group } \\
" \\
-\mathrm{C}=\mathrm{S} \text { and C-S group } \\
\text { "coordinate to } \mathrm{Cu}^{\mathrm{II}} \\
-\mathrm{C}-\mathrm{O}-\text { group }^{9}\end{array}$ & $\mathrm{DMX} 2 \mathrm{Cu}$ & $\begin{array}{l}3367 \\
1628 \\
1226 \\
1073 \\
1183 \\
1024 \\
1011\end{array}$ & $\begin{array}{l}\text { O-H Stretching } \\
\text { O-H Bending } \\
\text { 34 } \\
-\mathrm{C}=\mathrm{S} \text { and } \mathrm{C}-\text { Sgroup }^{35} \\
\text { " } \\
-\mathrm{C}=\mathrm{S} \text { and C-Sgroup } \\
{\text { "coordinate to } \mathrm{Cu}^{\mathrm{II}}}^{\mathrm{C}-\mathrm{O}-\text { group }^{35}}\end{array}$ \\
\hline DSX2 Ni & $\begin{array}{l}3355 \\
1629 \\
1227 \\
1083 \\
1186 \\
1043 \\
1011 \\
\end{array}$ & $\begin{array}{l}\text { O-H Stretching } \\
\text { O-H Bending }{ }^{20} \\
-\mathrm{C}=\mathrm{S} \text { and } \mathrm{C}-\mathrm{S} \text { group } \\
" \\
-\mathrm{C}=\mathrm{S} \text { and } \mathrm{C}-\mathrm{S} \text { group } \\
{ }^{9} \text { coordinate to } \mathrm{Ni}^{\mathrm{II}} \\
-\mathrm{C}-\mathrm{O} \text { - group }\end{array}$ & $\mathrm{DMX} 2 \mathrm{Ni}$ & $\begin{array}{l}3364 \\
1624 \\
1224 \\
1072 \\
1181 \\
1022 \\
1012 \\
\end{array}$ & $\begin{array}{l}\text { O-H Stretching } \\
\text { O-H Bending }{ }^{34} \\
-\mathrm{C}=\mathrm{S} \text { and } \mathrm{C}-\mathrm{S} \text { group } \\
" \\
-\mathrm{C}=\mathrm{S} \text { and } \mathrm{C}-\mathrm{S} \text { group } \\
\text { "coordinate to Ni } \mathrm{Ni}^{\mathrm{II}} \\
-\mathrm{C}-\mathrm{O}-\text { group }^{35}\end{array}$ \\
\hline
\end{tabular}

\section{CONCLUSIONS}

Xanthates DSX1, DSX2, DMX1 and DMX2 were synthesized by the chemical addition of $\mathrm{CS}_{2}$ with D- sorbitol and D-mannitol in basic medium using different ratio of sugar, a base and $\mathrm{CS}_{2}$. Although change the above ratio in chemical reaction, but isolated xanthates have the same properties as above xanthates. These xanthates have good ability to form complexes with metal ion $\mathrm{M}^{\mathrm{II}}\left(\mathrm{M}^{\mathrm{II}}=\mathrm{Cu}^{\mathrm{II}}\right.$ and $\left.\mathrm{Ni}^{\mathrm{II}}\right)$ The FT-IR spectral data revealed that the removal mechanism of $\mathrm{Cu}$ and $\mathrm{Ni}$ ion involves complexation. The sugars used are also obtained from natural sources; therefore the synthesized xanthates are inexpensive and ecofriendly. The synthetic procedure and isolation are easy to carry out. The experimental findings indicate that the newly synthesized xanthates are promising candidates, which could be used as complexing agents for the removal of $\mathrm{Cu}^{\mathrm{II}}$ and $\mathrm{Ni}^{\mathrm{II}}$ ion from wastewater.

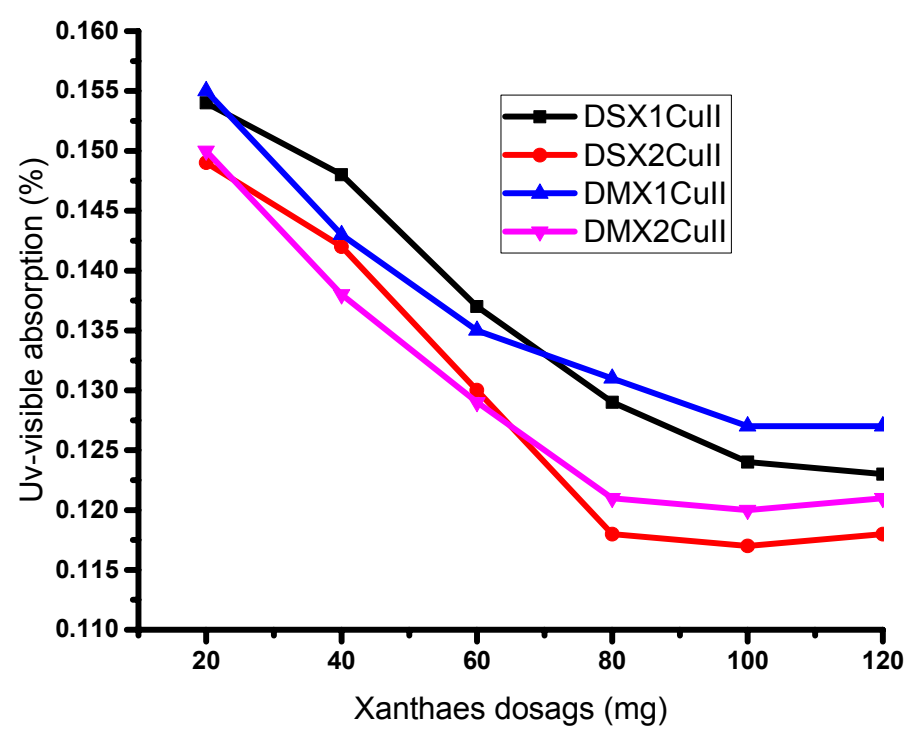

Fig. 2 - UV-visible absorption v/s xanthates dosage for $\mathrm{Cu}^{\mathrm{II}}$ ion solution. 


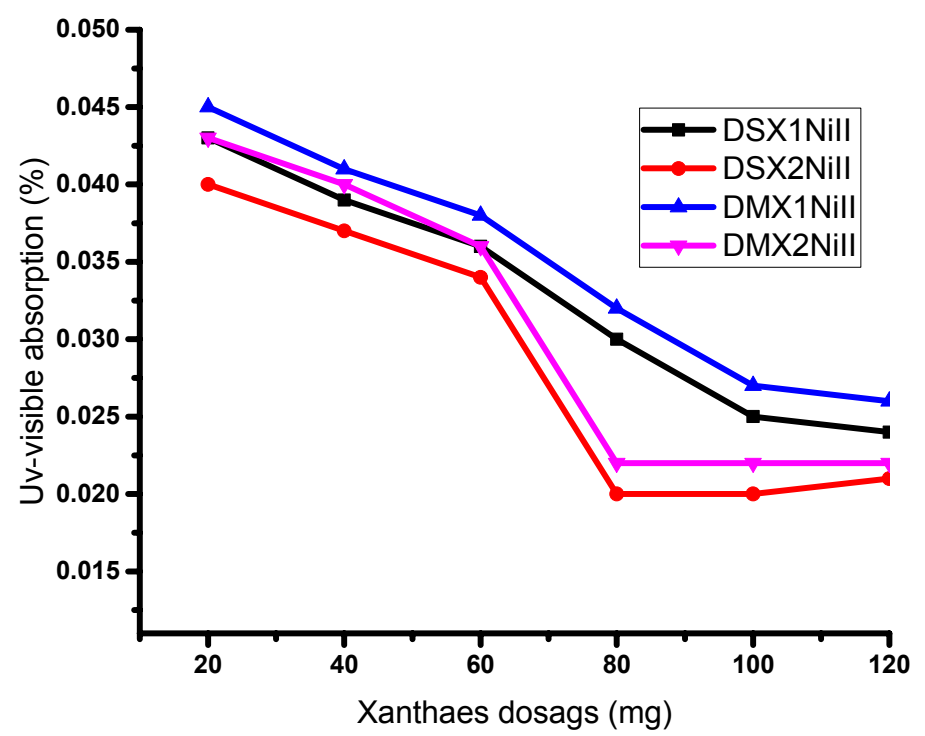

Fig. 3 - UV-visible absorption $\mathrm{v} / \mathrm{s}$ xanthates dosage for $\mathrm{Ni}^{\mathrm{II}}$ ion solution.

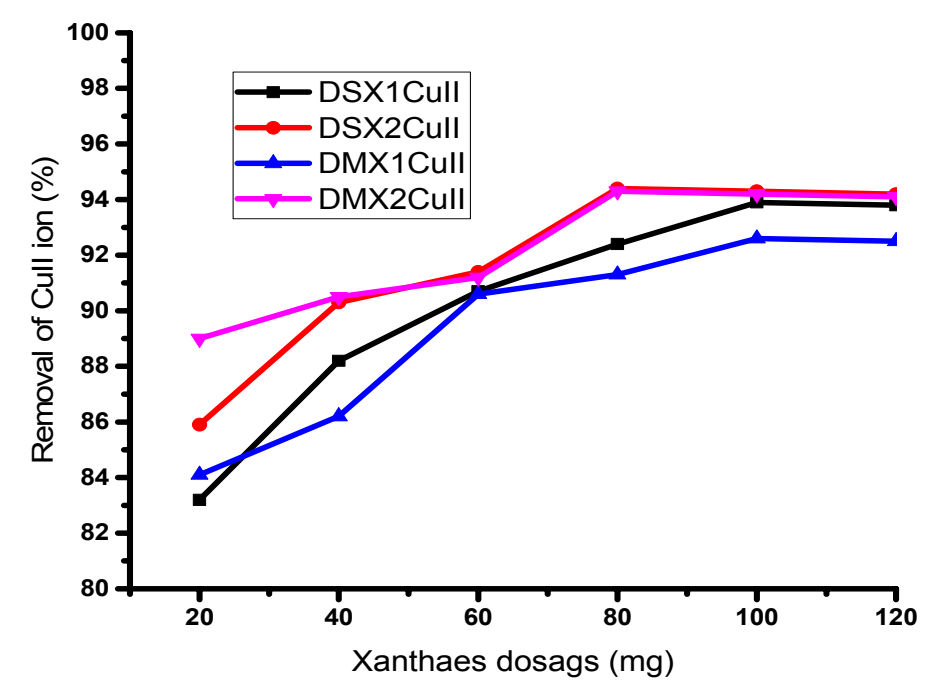

Fig. 4 - Effect of xanthates dosage on percentage removal of $\mathrm{Cu}^{\mathrm{II}}$ ion solution.

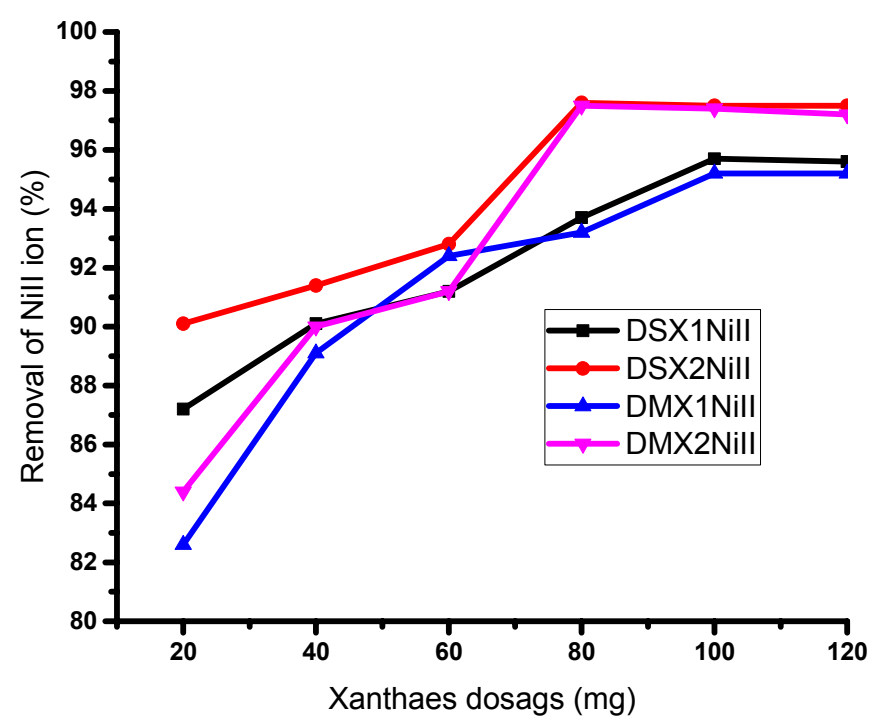

Fig. 5 - Effect of xanthates dosage on percentage removal of $\mathrm{Ni}^{\mathrm{iI}}$ ion solution. 
Acknowledgements. We gratefully thanks to authority of B. R.D. P. G. College, Deoria, to provide me doing research opportunity and also thanks to, Hon.Vice chancellor M. M. M. U. T. for providing research facilities.

\section{REFERENCES}

1. J. Li, B. Jiang, Y. Liu, C. Qiu, J. Hu, G. Qian, W. Guo and H. H. Ngo, J. Clean. Produ., 2017, 158,51-58.

2. Y. Chen, W. Zhang, S. Yang, A. Hobiny, A. Alsaedi and X. Wang, Sci. China Chem., 2016, 59, 412-419.

3. V. Zarezade, M. Behbahani, F. Omidi, H. S. Abandansari and G. Hesam, Rsc. Advan., 2016, 6, 103499-103507.

4. B. A. Lajayer, M. Ghorbanpour and S. Nikabadi, Ecotox. Environ. Safe., 2017, 145, 377-390.

5. A. Ahmed, M. A. A.Abdel, S. A. A. Abdulraheem and S. R. Moamen, Rev. Roum. Chim., 2019, 64, 817-828.

6. K. Feng and G. We, Intern. J. Polym. Sci., 2017, 2017, 1-9.

7. L. Guo, S. F. Zhang, B. Z. Ju, J. Z. Yang and X. Quan, J. Polym. Res., 2006, 13, 213-217.

8. B. Shahzad, M. Tanveer, A. Rehman, S. A. Cheema, S. Fahad, and A. Sharma, Plant Physio. Biochem., 2018, 132, 641-651.

9. A. Pourkhabbaz and H. Pourkhabbaz, Iran. J. Basic Med. Sci., 2012, 15, 636-644.

10. Z. Li, J. Chen, H. Guo, X. Fan, Z. Wen, M. H. Yeh, C. Yu, X. Cao and Z. L. Wang, Adv. Mater., 2016, 28, 2983-2991.

11. I. A. Aguayo-Villarreal, A. Bonilla-Petriciolet and R. MuñizValencia, J. Mol. Liq., 2017, 230, 686-695.

12. H. Xiyili, S. Çetintaş and D. Bingöl, Proc. Env. Prot., 2017, 109, 288-300.

13. A. Nath, P. P. Pande, Adv. Sci. Eng. Medi., 2020, 12, 105107.

14. Y. Ge and Z. Li, ACS Sust. Chem. Eng., 2018, 6, 7181-7192.

15. N. Ponomarev, O. Pastushok, E. Repo, B. Doshi and M. Sillanpä, ACS Appl. Nano Mater., 2019, 2, 5492-5503.

16. X. O. H. Zhang, S. L. Lai, J. Gao and L. Gao, React. Funct. Polym., 2020, 149, 104502; $\quad$ DOI 10.1016/j.reactfunctpolym.2020.104502.
17. M. Chen and N. P. Hankins., J. Water Proc. Eng., 2020, 34, 101170.

18. A. Olga, C. Ramírez, M. A. Omar, P. Arivalagan and R. R. Eldon, Curr. Pollu. Rep., 2020, 6, 8-27.

19. M. Hassan, R. Naidu, J. Du, Y. Liu and F. Qi, Sci. of The Total Env., 2020, 702, 134893.

20. J. Zhang, Y. Ge, Z. Li and Y. Wang, J. Environ. Manag., 2020, 256, 109969.

21. Q. Wang, C. Zheng, W. Cui, F. He, J. Zhang, T. C. Zhang and C. He, Chemic. Eng. J., 2019, 123581.

22. H. Fan, X. Ma, S. Zhou, J. Huang, Y. Liu and Y. Liu, Carbohydrate Polym., 2019, 213, 39-49.

23. S. Zhang, H. Chen, S. Zhang, C. Kai, M. Jiang, Q. Wang and Z. Zhou, Cellulose, 2019, 26, 3437-3453.

24. A. Q. Khan, A. U. Rahman, M. Yaseen, H. U. Rashid, M. Iqbal and M. U. Rehman, Rev. Roum. Chim.,2019, 64, 949-963.

25. A. Kong, Y. Ji, H. Ma, Y. Song, B. He and J. Li, J. Clean. Produ., 2018, 192, 801-808.

26. A. Nath and P. P. Pande, Progressive Research - An International, J., 2018, 13, 600-603.

27. A. Nath, Anamica, M. Yadav, R. Kumar and P. P. Pande, 2019 IEEE Uttar Pradesh Section International Conference on Energy, Environment \& Material Sciences (ICEEM) Accepted.

28. J. R. Pledge, T. S. Young and G. S. Wu, J. Macrmol. Sci. Chem., 1986, 42, 415-426.

29. Q. Chang, X. Hao and L. Duan, J. Hazar. Mater, 2008, 159, 548-553.

30. G. Exarches and S. Robinson, J. Steed, Polyh,.2001, 20, 2951.

31. M. J. Co and E. R. T. Tiekink, Kristallog, 1996, 211, 111113.

32. E. M. L. Vidal, G. L. Gregory, G. K. Khon and A. Buchaed, Polym. Chem., 2018, 1577-1582.

33. N. Wang, X. Xu, H. Li, J. Zhai, L, Yuan, K. Zang and H. Yu, Ind. Eng.Chem. Res., 2016, 55, 4960-4968.

34. Z. J. Patel, M. C. Pate, P. M Chaturbhuji, V. A. Patel and D. R. Patel, Res. J. Chem. Env.., 2020, 24, 73-77.

35. S. A. F. Aeed and I. A. Emam , A Sci. J. Koya Univ., 2018, 6, 33-37. 
